\title{
Conservação pós-colheita da lima ácida "Tahiti" tratada com 1-metilciclopropeno
}

\author{
Julius Blum ${ }^{1}$ \\ Ricardo Antonio Ayub ${ }^{2 *}$ \\ ${ }^{1}$ PPG de Agronomia, Universidade Estadual de Ponta Grossa (UEPG) \\ juliusblum@yahoo.com.br \\ ${ }^{2}$ Departamento de Fitotecnia e Fitossanidade, UEPG, Setor de Ciências Agrárias \\ Av. Carlos Gal. Cavalcante, 4748, CEP 84030-900, Ponta Grossa - PR, Brasil \\ rayub@uepg.br \\ *Autor para correspondência
}

Submetido em 10/09/2007

Aceito para publicação em 14/12/2007

\section{Resumo}

Embora a lima ácida 'Tahiti' não seja um fruto climatérico, o etileno está envolvido na degradação das clorofilas da casca, podendo o 1-metilciclopropeno (1- MCP) ser eficiente na conservação da cor e da qualidade do fruto. Com o objetivo de testar esta hipótese, foi realizado um estudo com frutos no estádio de coloração C2. Os tratamentos foram a exposição dos frutos às concentrações de 0,$0 ; 0,5$ e 1,0mg L-1 de 1-MCP em câmara hermeticamente fechada por 12 horas. A armazenagem foi à temperatura de $24^{\circ} \mathrm{C}$ por 20 dias, com avaliações a cada 5 dias. Ocorreram aumentos lineares para a escala de coloração da casca, Sólidos Solúveis (SS) e "ratio" e aumento quadrático para perda de peso em função do tempo. O tratamento com 1,0mg L-1 de 1-MCP reduziu a velocidade de perda de cor verde, evitou a perda de massa e ocasionou um ligeiro aumento do pH do suco. Não ocorreram variações significativas nos teores de SS e clorofilas em função do tratamento com 1-MCP. O "ratio" foi maior para o tratamento com $1,0 \mathrm{mg} \mathrm{L}^{-1}$, sem contudo diferir da testemunha.

Unitermos: etileno, Citrus latifolia, senescência, amadurecimento de frutos

\section{Abstract}

Post harvest conservation of "Tahiti" lime treated with 1-metylcyclopropene. Although 'Tahiti' lime is not a climateric fruit, ethylene is involved in degradation of the chlorophylls of the skin, and 1-MCP can be efficient in color and fruit quality conservation. With the objective of testing 1-MCP, a study was carried out with $\mathrm{C} 2$ coloration stadium fruits. The treatments consisted of exposure of the fruits to the concentrations of $0.0,0.5$ and $1.0 \mathrm{mg} \mathrm{L}^{-1}$ of $1-\mathrm{MCP}$, followed by storage at $24^{\circ} \mathrm{C}$ for 20 days, with evaluations at 5 day intervals. Linear increases for the scale of coloration of the skin, soluble solids (SS), and the ratio and quadratic increase for loss of fresh weight occurred in function of the time. The treatment with $1 \mathrm{mg} \mathrm{L}^{-1}$ of $1-\mathrm{MCP}$ reduced the loss of green coloration of the skin, preventing the loss of mass and provoking an increase in $\mathrm{pH}$ of the juice. No significant variations in the SS or chlorophylls in function of the treatments with 1-MCP occurred. The major ratio was observed with $1 \mathrm{mg} \mathrm{L}^{-1}$, but it did not differ from the control.

Key words: ethylene, Citrus latifolia, ripening fruit 


\section{Introdução}

No ano de 2006, em 50.783ha de cultivo, o Brasil produziu 1.030.531t de lima ácida 'Tahiti' das quais foram exportadas cerca de $51.440 \mathrm{t}$ ( $5 \%$ do total produzido) (Reetz, 2007). Apesar do volume exportado estar crescendo, a participação do mercado externo ainda é muito baixa e o Brasil precisa melhorar a qualidade pós-colheita desta fruta.

A coloração externa da casca é um dos principais atributos de qualidade e um fator determinante na comercialização de limões (Mazzuz, 1996). A manutenção da cor verde nos frutos é essencial para a exportação. Nos frutos cítricos a degradação das clorofilas e a síntese ou manifestação dos carotenóides mudam a coloração da casca (Baldwin, 1993). Esta mudança na coloração é influenciada pela espécie, cv. copa e porta-enxerto, temperatura, umidade relativa do ar, luminosidade, posição do fruto na planta, nutrição e irrigação (Casas e Mallent, 1988a; Casas e Mallent, 1988b; Agustí e Almela, 1991; Mazzuz, 1996). A degradação das clorofilas é acentuada pelo etileno (Latche et al., 1995) que promove as ações das enzimas clorofilase e oxidases, desaparecendo a cor verde (Yamauchi et al., 1997). A qualidade dos frutos depende do estado adequado de maturação, e está relacionada ao aumento da taxa respiratória (Abeles et al., 1992). Os frutos em geral respondem à concentração de $0,1 \mu \mathrm{L} . \mathrm{L}^{-1}$ de etileno na atmosfera de armazenagem, reduzindo assim sua conservação (Sisler e Serek, 1997). Este hormônio se liga às moléculas receptoras, provavelmente proteínas membranares, ativando o amadurecimento (Golding et al., 1998).

O 1-metilciclopropeno (1-MCP) é um produto que atua inibindo a ação do etileno, pela sua interação com o sítio receptor do etileno por longo período (Sisler e Serek, 1997), prevenindo a formação de complexos ativos relacionados à ação do etileno (Watkins 2002; Binder e Bleecker 2003) e à senescência do fruto.

Este estudo foi realizado com o objetivo de avaliar a eficiência do 1-MCP na conservação da cor verde e da qualidade dos frutos da lima ácida 'Tahiti' armazenada à temperatura de $24^{\circ} \mathrm{C}$.

\section{Material e Métodos}

Frutos de lima ácida 'Tahiti', colhidos em pomar comercial no estádio de coloração C2 no dia 13 de Junho de 2007, foram imediatamente levados ao Laboratório de Biotecnologia Aplicada a Fruticultura, da Universidade Estadual de Ponta Grossa, para a aplicação dos tratamentos.

A aplicação foi realizada no dia 14/06/07 com a utilização de uma câmara experimental, hermeticamente fechada, com capacidade de $0,186 \mathrm{~m}^{3}$, onde os frutos foram expostos às concentrações de $0,0,0,5$ e $1,0 \mathrm{mg}$ $\mathrm{L}^{-1}$ de 1-MCP $\left(34,4\right.$ e $68,8 \mathrm{~g} \mathrm{~m}^{-3}$ do produto comercial SmartFresh ${ }^{\mathrm{TM}}$ ) durante 12 horas, sob temperatura de $24^{\circ} \mathrm{C}$. Após a retirada da câmara, os frutos foram armazenados à $24^{\circ} \mathrm{C}$, UR $70 \pm 10 \%$ por 20 dias.

A qualidade dos frutos foi avaliada na colheita $\mathrm{e}$ em intervalos de 5 dias durante a armazenagem. Analisou-se o teor de sólidos solúveis (SS) determinados por refratometria em ${ }^{\circ}$ Brix; a acidez titulável, por titulação com $\mathrm{NaOH}$ sendo o resultado expresso em \% de ácido cítrico; o "ratio"; o pH; a perda de massa fresca; a coloração da casca [2- C2 (verde escuro brilhante); 3 - C3 (verde claro brilhante); 4 - C4 (verde/amarelo); 5 - C5 (amarelo) e 6 (casca escurecida), adaptação da escala da Hortibrasil (2007)] e a concentração de clorofilas na casca, de acordo com os métodos descritos por Arnon (1949).

Os tratamentos foram arranjados em um fatorial 3 x 5 ( 3 concentrações e 5 tempos), distribuídos inteiramente ao acaso. Para coloração foram avaliados 12 frutos, onde cada fruto foi considerado uma repetição, e as demais análises foram realizadas em amostras compostas de 3 frutos, com quatro repetições. A análise de variância dos dados foi feita pelo teste $\mathrm{F}$ e as médias foram avaliadas pelo teste de Tukey ao nível de $5 \%$.

\section{Resultados e Discussão}

Não houve interação significativa para cor, SS, $\mathrm{pH}$, perda de massa, clorofilas e "ratio", portanto, o efeito dos fatores tempo de armazenamento e tratamentos com 1-MCP serão discutidos separadamente para estas variáveis. 
A degradação das clorofilas com o tempo de armazenamento foi evidente em todos os tratamentos, perdendo a cor verde linearmente com o tempo, indicada pela evolução crescentes das notas atribuídas aos frutos (Figura 1), no entanto, o tratamento com $1 \mathrm{mg} \mathrm{L} \mathrm{L}^{-1}$ de 1-MCP a redução da coloração verde dos frutos foi menos acentuada que nos demais tratamentos (Tabela 1), concordando com os resultados obtidos por Jomori et al. (2003). Constatamos, portanto, que o 1-MCP pode melhorar a conservação de frutos não climatéricos, como é o caso da lima ácida, e que o etileno tem papel importante na degradação das clorofilas em concordância com Latche et al. (1995). A prevenção da formação de complexos ativos relacionados à ação do etileno relatada por Watkins (2002) e Binder e Bleecker (2003) provavelmente evitou a degradação das clorofilas que é acentuada pelo etileno mesmo quando produzido em baixas concentrações.

A provável formação de complexos ativos com o etileno tornou o fruto mais sensível à perda de massa. A perda de massa fresca nos frutos tratados com $1 \mathrm{mg} \mathrm{L}^{-1}$ de 1 -MCP foi em média $8,4 \%$ menor que a dos demais tratamentos (Tabela 1). Ocorreu aumento quadrático da perda de massa com o passar do tempo. As perdas acumuladas durante o período de 20 dias foram de aproximadamente 25\% (Figura 2).

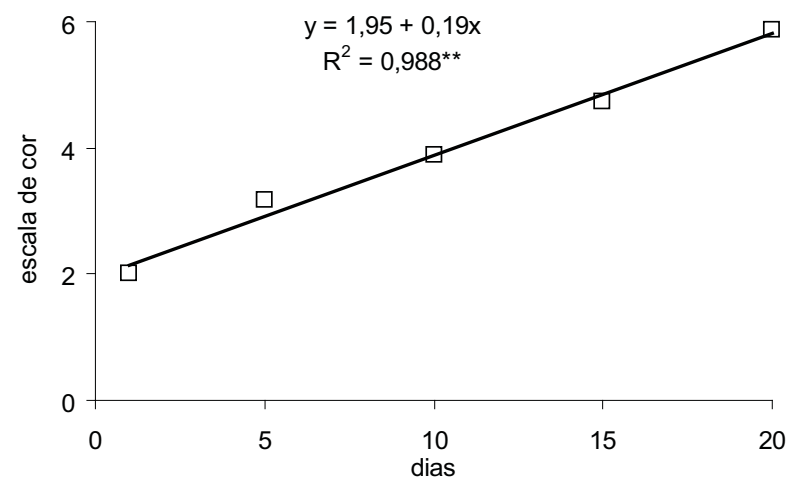

FIGURA 1: Evolução da escala de cor da casca do fruto da lima ácida 'Tahiti' tratadas com 1-MCP em função do tempo de armazenagem a temperatura ambiente. Cada ponto é a média de 12 repetições dos 3 tratamentos com 1 MCP. Ponta Grossa, PR, 2007.
A perda de massa é um parâmetro importante, pois além de prejuízos diretos causados pela diminuição da massa dos frutos, esta associada ao aspecto coloração e de frescor. $\mathrm{O}$ aspecto de fruta fresca com manutenção da cor verde se manteve até 15 dias após a aplicação no tratamento com $1 \mathrm{mg} \mathrm{L}^{-1}$ de 1-MCP. Os frutos da testemunha e do tratamento com $0,5 \mathrm{mg} \mathrm{L}^{-1}$ apresentavam bom aspecto apenas até os 10 dias de armazenagem à temperatura de $24^{\circ} \mathrm{C}$. É importante destacar que a umidade relativa do ar oscilou entre 60 e $80 \%$, provocando uma perda de massa acentuada e rápido escurecimento da casca.

TABELA 1: Valores médios da cor, sólidos solúveis, $\mathrm{pH}$, perda de massa fresca, clorofilas e "ratio" de frutos de lima ácida Tahiti tratados ou não com 1-MCP. Cada valor é a média de 5 tempos e as respectivas repetições. Ponta Grossa, PR, 2007.

\begin{tabular}{ccccccc}
\hline $\begin{array}{c}\text { Tratamento } \\
\text { MCP } \\
\left(\mathbf{m g ~ L}^{-1}\right)\end{array}$ & Cor & $\begin{array}{c}\text { SS } \\
\text { Brix }\end{array}$ & $\mathbf{p H}$ & $\begin{array}{c}\text { Perda de } \\
\text { massa } \\
\text { fresca }(\mathbf{g})\end{array}$ & Clorofilas "ratio" \\
\hline 0,0 & $4,1 \mathrm{a}$ & $7,9 \mathrm{a}$ & $2,45 \mathrm{~b}$ & $20,2 \mathrm{a}$ & $0,87 \mathrm{a}$ & $1,28 \mathrm{ab}$ \\
0,5 & $4,0 \mathrm{a}$ & $8,0 \mathrm{a}$ & $2,44 \mathrm{~b}$ & $20,6 \mathrm{a}$ & $0,87 \mathrm{a}$ & $1,22 \mathrm{~b}$ \\
1,0 & $3,7 \mathrm{~b}$ & $8,1 \mathrm{a}$ & $2,51 \mathrm{a}$ & $18,6 \mathrm{~b}$ & $0,82 \mathrm{a}$ & $1,33 \mathrm{a}$ \\
\hline
\end{tabular}

Médias seguidas de uma mesma letra na coluna não diferem pelo teste de Tukey $(\mathrm{P} \leq 0,05)$.

A aplicação de $1 \mathrm{mg} \mathrm{L}^{-1}$ de 1-MCP ocasionou um ligeiro aumento do $\mathrm{pH}$ do suco da lima ácida (Tabela 1). Possivelmente, este efeito tenha ocorrido devido à concentração de ácidos nos demais tratamentos em função da maior perda de água. As variações do $\mathrm{pH}$ do suco sofreram variações mínimas com o passar do tempo (Figura 3), pois por um lado ocorre a concentração de ácidos e diminuição do $\mathrm{pH}$, por outro ocorre a degradação dos ácidos orgânicos devido ao amadurecimento (Mercado-Silva et al., 1998). 


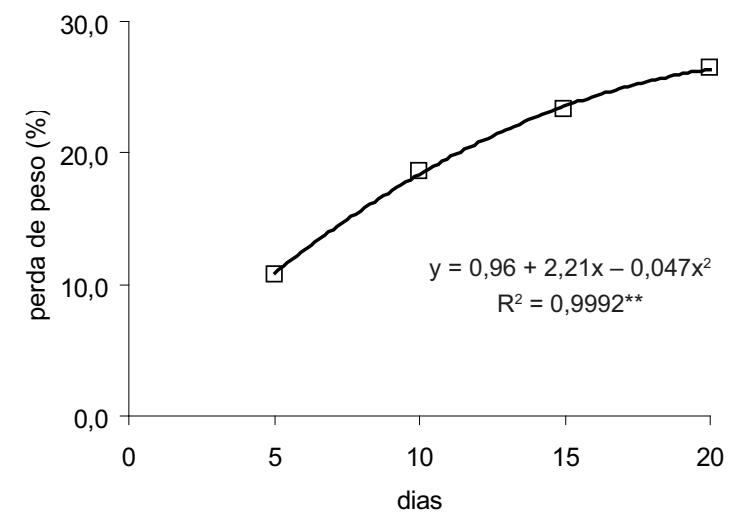

FIGURA 2: Evolução da perda de massa fresca de frutos de lima ácida 'Tahiti' tratados com 1-MCP em função do tempo de armazenagem a temperatura ambiente. Cada ponto é a média de 4 repetições dos 3 tratamentos com 1-MCP. Ponta Grossa, PR, 2007.

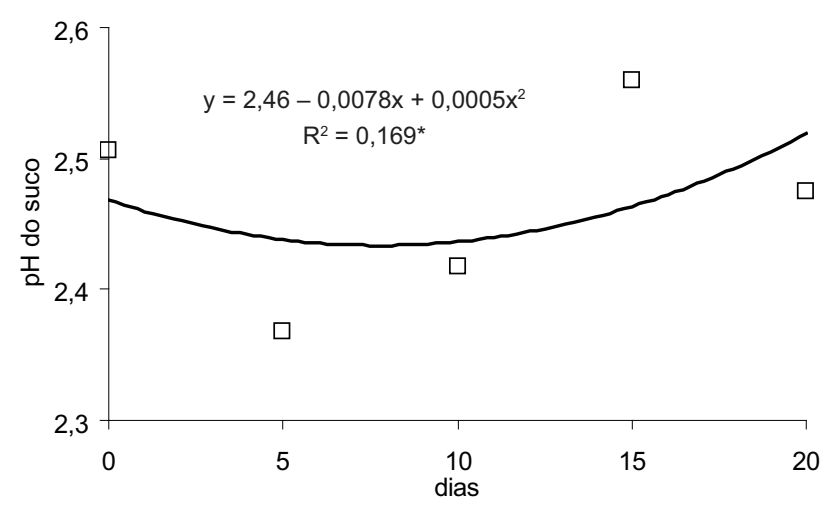

FIGURA 3: Evolução do pH do suco em frutos de lima ácida 'Tahiti' tratados com 1-MCP em função do tempo de armazenagem a temperatura ambiente. Cada ponto é a média de 4 repetições dos 3 tratamentos com 1-MCP. Ponta Grossa, PR, 2007.

A acidez total titulável sofreu comportamento diferente em função do tempo, aumentando linearmente nos frutos testemunhas, e de forma quadrática com um declínio inicial e aumento a partir de 10 dias de armazenagem nos frutos tratados com 1-MCP (Figura 4). Esta variação não afetou a qualidade dos frutos, uma vez que a alta acidez associada ao baixo $\mathrm{pH}$ é condição normal nesse tipo de fruto.

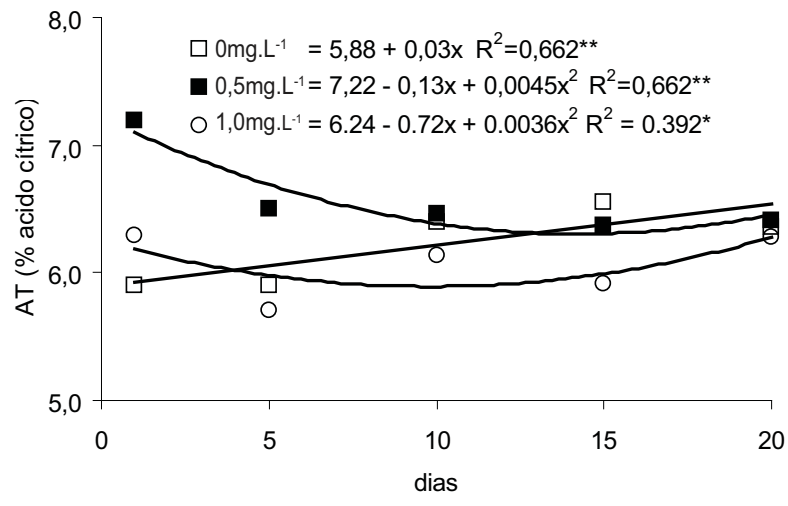

FIGURA 4: Evolução da acidez titulável do fruto de lima ácida "Tahiti" tratados com 1-MCP em função do tempo de armazenagem a temperatura ambiente. Ponta Grossa, PR, 2007.

Não ocorreram diferenças significativas entre os teores de sólidos solúveis dos tratamentos com 1-MCP e a testemunha (Tabela 1). Os sólidos solúveis aumentaram linearmente com o tempo de armazenamento (Figura 5), provavelmente pela concentração de substancias no suco devido a perda de água. O "ratio" foi maior para o tratamento com 1,0 $\mathrm{mg} \mathrm{L}^{-1} 1$-MCP sem, contudo, diferir da testemunha (Tabela 1), e ocorreu aumento linear do "ratio" em função do tempo (Figura 6).

A determinação da quantidade de clorofilas da casca da lima ácida foi efetuada a 0,5 e 10 dias de armazenamento, porém não houve diferenças entre tratamentos (Tabela 1) e nem a degradação das clorofilas com o tempo. Essa ausência de efeito deve-se a falha do método utilizado, tendo em vista que se utilizou massa de casca para realizar a determinação, e como ocorreram diferenças na perda de massa fresca entre os tratamentos e a elevada perda de massa com o tempo, as clorofilas sofreram diferentes diluições. $\mathrm{O}$ método adequado para essa determinação deve levar em consideração a área de casca amostrada. 


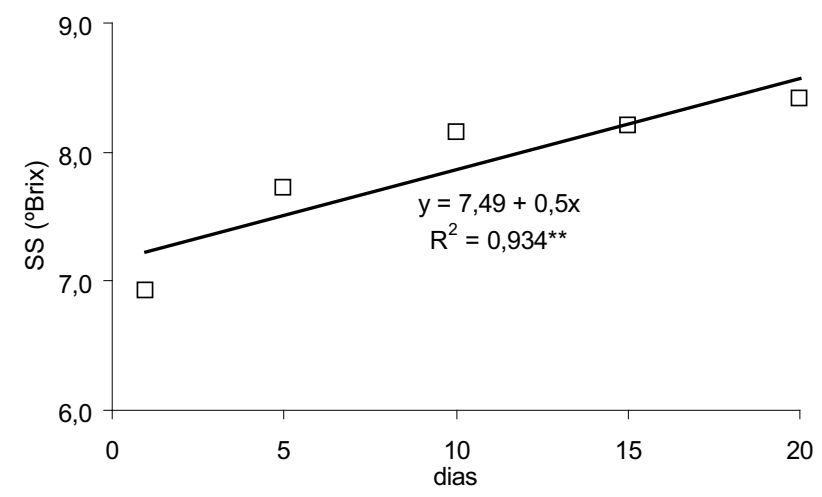

FIGURA 5: Evolução dos sólidos solúveis nos frutos de lima ácida 'Tahiti' tratados com 1-MCP em função do tempo de armazenagem a temperatura ambiente. Cada ponto é a média de 4 repetições dos 3 tratamentos com 1-MCP. Ponta Grossa, PR, 2007.

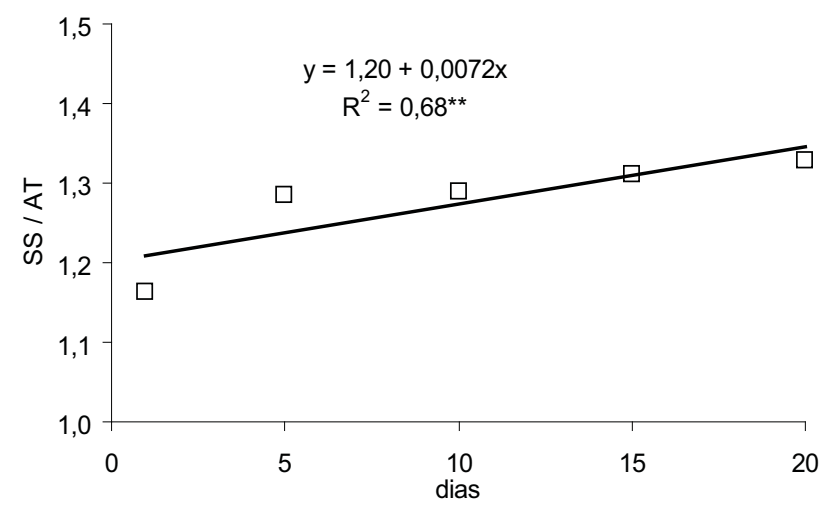

FIGURA 6: Evolução do "ratio" em frutos de lima ácida 'Tahiti' tratados com 1-MCP em função do tempo de armazenagem a temperatura ambiente. Cada ponto é a média dos 3 tratamentos com 1-MCP e 4 repetições. Ponta Grossa, PR, 2007.

A partir dos resultados obtidos foi possível concluir que a concentração de $1,0 \mathrm{mg} \mathrm{L}^{-1}$ de 1 -MCP retardou a perda de cor verde da casca e a perda de massa fresca, do fruto de lima ácida 'Tahiti'.

\section{Referências}

Abeles, F. B.; Morgan, P. W.; Saltveit, M. E. 1992. Ethylene in plant biology. $2^{\text {nd }}$ ed. Academic Press, San Diego, USA, 414pp.

Agustí, M.; Almela, V. 1991. Aplicación de fitorreguladores en citricultura. AEDOS Ed., Barcelona, España, 261pp.
Arnon, D. 1949. Copper enzymes inisolated chloroplasts. Polyphenoloxidase in beta vulgaris. Plant Physiology, 24 (1): 1-15.

Baldwin, E. A. 1993. Citrus fruit. In: Seymour, G. B.; Taylor, J. E.; Tucker, G. A. Biochemistry of fruit ripening. Chapman \& Hall, London, UK, p.255-271.

Binder, B. M.; Bleecker, A. B. 2003. A model for ethylene receptor function and 1-methycyclopropene action. Acta Horticulturae, 628: $177-187$.

Casas, A.; Mallent, D. 1988a. El color de los frutos cítricos. I. Generalidades. II. Factores que influyen en el color. Influencia de la especie, de la variedad y de la temperature. Revista de Agroquímica y Tecnología de Alimentos, 28 (2): 185-202.

Casas, A.; Mallent, D. 1988b. El color de los frutos cítricos. I. Generalidades. II. Factores que influyen en el color (continuación). Influencia de la fertilización, del portainjerto y otros. Revista de Agroquímica y Tecnología de Alimentos, 28 (3): 344-356.

Golding, J. B.; Shearer, D.; Wyllie, S. G.; McGlasson, W. B. 1998. Application of 1-MCP and propylene to identify ethylene-dependent ripening processes in mature banana fruit. Post harvest Biology and Technology, 14: 87-98.

Hortibrasil. 2007. Coloração. Disponível em <http://www.hortibrasil.org.br/ classificacao/limao/arquivos/coloracao.html>. Acesso em 03 de maio de 2007.

Jomori, M. L. L.; Kluge, R. A.; Jacomino, A. P.; Tavares, S. 2003. Conservação refrigerada de lima ácida 'Tahiti': Uso de 1-metilciclopropeno, ácido giberélico e cera. Revista Brasileira de Fruticultura, 25 (3): 406-409.

Latche, A.; Ayub, R.; Martinez, G.; Guis, M.; Ben Amor, M.; Rombaldi, C.; Pech, J. C.; Bouzayen, M. 1995. Biosynthèse et mode d'action de 1'hormone végétale éthylène. Fruits, 50: 379-96.

Mercado-Silva, E.; Benito-Bautista, P.; Garcia-Velasco, M. A. 1998. Fruit development, harvest index and ripening changes of guavas produced in central México. Postharvest Biology and Technology, 13:142-150.

Mazzuz, C. F. 1996. Calidad de frutos cítricos: manual para su gestion desde la recoleccion hasta la expedicion. Ediciones de Horticultura, Barcelona, Espana, 317pp.

Reetz, E. R. 2007. Anuário brasileiro da fruticultura. Ed. Gazeta Santa Cruz, Santa Cruz do Sul, Brasil, 136pp.

Sisler, E. C.; Serek, M. 1997. Inhibitors of ethylene responses in plants at the receptor level: Recent developments. Plant Physiology, 100: $577-582$.

Watkins, C. B. 2002. Ethylene synthesis, mode of action, consequences and control. In: Knee, M. (ed.). Fruit quality and its biological basis. Sheffield Academic Press, Sheffield, UK, p.180-224.

Yamauchi, N.; Akiyama, Y.; Kako, S.; Hashinaga, F. 1997. Chlorophylly degradation in Wase satsuma mandarin (Citrus unshiu Marc.) fruit with on-tree maturation and ethylene treatement. Scientia Horticulturae, 71 (1/2): 35-42. 